\title{
THE APPEARANCE OF CARRIERS AND THE ORIGINS OF MONEY
}

\author{
José Noguera \\ CERGE-EI, Charles University \\ P.O. Box 882, Politických vězňů 7, 11121 Prague 1
}

Phone: 420-2-240.05.107

\begin{abstract}
The purpose of this essay is to analyze the circumstances where a monetary economy dominates over a redistributive barter economy in which there is not an absence of double coincidence of wants problem. For this purpose, we develop a spatial general equilibrium model where individuals must trade with intermediaries to acquire the consumption goods that they need; exchange is costly, there is no trust, and individuals act in their own interest to maximize their utilities. The model is also used to address a number of issues in monetary economics like explaining the historical emergence of commodity-money, valued fiat money, the welfareenhancing role of money, equilibria with several mediums of exchange, and split between the utility and the medium of exchange value of the good that serves as a medium of exchange. It also provides some interesting links between the monetary and urban economics literatures.
\end{abstract}

\begin{abstract}
$\underline{\text { Abstrakt }}$
Článek analyzuje podmínky, za nichž je monetární ekonomika efektivnější než redistributivní ekonomika založená na směně zboží a potýká se s problémem „oboustranné koincidence potřeb.“ $\mathrm{K}$ tomuto účelu je užito modelu celkové rovnováhy $\mathrm{v}$ prostoru. Jednotliví spotřebitelé musí obchodovat se zprostředkovateli, aby získali požadované spotřební zboží. Směna je nákladná, všichni jedinci sledují své vlastní zájmy (tj. maximalizují své užitkové funkce), a důvěra bez záruk neexistuje. Model je dále použit $\mathrm{k}$ osvětlení mnoha problematických bodů monetární ekonomie, jako je historický vznik zbožových a později papírových peněz; role peněz při zvyšování společenského blahobytu; rovnovážný stav, ve kterém se použivá najednou několik platidel; a rozpor mezi užitnou (faktickou) a směnnou hodnotou zboží, které je používáno jako platidlo. Díky využití konceptu celkové rovnováhy v prostoru spojuje model zajímavým způsobem monetární a urbanistickou literaturu.
\end{abstract}

JEL Classification: E00, D61, E41, N1, R11

Key Words: barter, medium of exchange, city size, carrier, merchant, transaction cost.

I am especially indebted to Alex Anas for extensive discussion and commentary on earlier drafts of this paper. I also thank David Laidler and Avner Shaked for useful comments. Responsibility for any error or imperfection remains strictly my own. 


\title{
THE APPEARANCE OF CARRIERS AND THE ORIGINS OF MONEY
}

\author{
José Noguera, CERGE-EI, Charles University, Prague
}

Socrates: A city is a response to human needs. No human being is self-sufficient and all of us have many wants... The origin of every real city is human necessity... The first and greatest necessity is food... Next a place to live; third, clothing and the like... Then we must ask how our city will provide these things. A farmer will be needed, and a builder and a weaver as well... Then how should they proceed? ... Should he produce food for his own needs alone devoting only a fourth of his total effort to that kind of work? Then he could allot the other three-fourth of his time to building a house, making clothes, and cobbling shoes. Choosing the latter, he wouldn't have to bother about associating with others; he could supply his own wants and be his own man.

Adeimantus: I don't think he should try to do everything. He should concentrate on producing food.

Socrates: I agree that this would probably be the better way... We can conclude, then, that production in our city will be more abundant and the products more easily produced and of better quality if each does the work nature has equipped him to do, at the appropriate time, and is not required to spend time on other occupations... Then there will be a market place and money as a medium of exchange... Supposing the farmer or other craftsman brings his produce to market but does not arrive at the same time as those who would buy from him. Would he sit idly in the market place, wasting time he could otherwise devote to productive work?

Adeimantus: Not at all. There will be men at the market who will offer their services to remedy the situation by acting as salesmen...

Socrates: $\quad$ So the need for money in the exchange of goods produces the class we know as tradesmen.

Plato, The Republic, Book II (369-371)

\section{INTRODUCTION}

People gather to overcome difficulties. Among these difficulties are people's needs to protect themselves from their enemies or the hazards of nature. People also gather to help each other to build a better life together. One way to attain this goal is by joining efforts to obtain the goods needed to survive. These ideas were present in Socrates' mind when he said, "the origin of every real city is human necessity." 
The next step in this argument is that, once people decided to live in cities, they realized that they could better satisfy their needs if they specialized, and the idea of the division of labor is also in Socrates and Adeimantus' dialog. It is interesting to notice that according to Socrates, as well as Plato, Aristotle, and likely many other Greek philosophers before them, specialization does not cause an increase in efficiency per se, but is a result of allowing everyone to specialize in what each finds more suitable. The reasoning continues by arguing that specialization brings the need of exchange, and difficulties in exchange are overcome by money.

The influence of these ideas survived in Smith (1776). He refines these arguments and asserts that the division of labor was a very slow and gradual process that caused a considerable improvement in productivity, is limited by the extension of the market, and brought the need for trucking and bartering. Smith continues to argue that once the division of labor has been thoroughly established so that an individual produces only a very small part of his wants, individuals live by exchanging, and a commercial society appears, bringing the need of a medium of exchange.

A century later, Jevons (1875) strongly emphasizes that the difficulties in exchange came from the lack of a double coincidence of wants, and that money appeared to resolve these frictions. Menger (1892) also stresses the use of money as a medium of exchange, and points out three other important features. The first is that people accept money as long as others do as well. The second is that the appearance of money was an unconscious and gradual process involving a learning process through several generations, and third, this process was the result of individuals' attempts to maximize their utilities.

For many years, after this literature, no important essay on the origins of money based on the absence of a double coincidence of wants was written until Jones (1976) developed a 
model based on Menger's ideas. Kiyotaki and Wright (1989) sets up a random matching model in which several objects are potential mediums of exchange, but only one of them, based on its physical properties, is ultimately chosen for that role. They gave origin to an important literature that uses search theory to motivate the existence of a medium of exchange. This kind of models usually assumes the existence of a specialized economy where each individual produces only one good and wants to consume a bundle of goods. There is no social organization, so to obtain this bundle, each individual randomly searches for one other individual wanting to exchange the good that he produces for the bundle that he needs. Those who do not succeed bartering in a particular period receive zero utility in that period, so there is a probability that a number of individuals starve due to the inconvenience of the barter system; then, a medium of exchange emerges as a way to solve the inconvenience of barter.

Although this logically well-structured theory based on the random matching assumption is able to explain many facts about monetary economies, it misses a couple of ideas already present in Socrates and Adeimantus' dialogue. The first is the existence of a city where people gather and exchange the goods they need. The other is the presence of middlemen to resolve frictions caused by the lack of a double coincidence of wants. If each individual produces only one good, then nobody but a middleman has a bundle of goods. However, people usually know who and where the middleman is, so if someone needs to barter, he simply needs to visit the middleman. In this case, there is no random matching. This view is consistent with Duffy and Ochs (1999)' findings in an experimental study on the emergence of money. They conclude that individuals have a strong tendency to play fundamental rather than speculative strategies even in environments where speculative strategies yield higher payoffs. In fact, as Laidler (1997, pg. 1920) asserts: "The basic insight about the role of mutually consistent beliefs in supporting monetary exchange yielded by models like that of Kiyotaki and Wright is 
therefore important, even though such models seem incapable of getting the grips with the historical emergence of money."

Historians and anthropologists have found many elements supporting the importance of social organization and middlemen in the genesis of money. For example, Renfrew and Bahn (1996, pg. 351-353) argue that once the economy reaches a minimum level of technical progress, the division of labor and barter intensifies together in a system in which commodities travel "Down-the-Line". At the beginning, there is no middleman and no money, and individuals meet randomly. Yet, once individuals learn how to locate each other, a more systematic barter starts. This barter economy begins, first, as a reciprocity system in the way of exchanges of gifts among people well known to each other in well-defined contexts. Over time, a redistributive barter economy with centralized and traveling merchants emerges: goods are sent to a market center and then redistributed; individuals produce one or a few goods but consume many. In the redistributive system, exchange operates better than in the unstructured barter, overcoming the absence of a double coincidence of wants problem. In all likelihood, money appears under this system. This view has been widely accepted by anthropologists after Polanyi (1957).

An important point that remains to ascertain is what makes money arise out of a redistributive barter economy. A theory explaining this process rests on the foreign trade. However, in spite that Phoenicia were a high mercantile people, they usually confined to the level of those with whom they traded, whether barter or monetary exchange system, see Ederer (1964). Clower (1995) provides a different explanation and asserts that, as an economy grows, merchants obtain benefits by becoming specialized traders, causing frictions among individuals that are resolved with the use of a medium of exchange. Howitt and Clower (2000) use computer simulation in an artificial generated economy to provide support to this idea: agents follow rules 
of thumb and monetary exchange emerges by an evolutionary process. Yet, Egyptians during the Old Kingdom always kept a very centralized barter structure out of which a medium of exchange emerged during an undetermined period between the IV and VII Dynasties.

Hicks $(1969,1989)$ suggests that people used a unit of account to facilitate transactions, and that this unit of account eventually emerged as a medium of exchange. He also emphasizes the importance of the geographical spread for the emergence of a medium of exchange. Nevertheless, no formal analytical model has been written to explain the circumstances that made possible this object to appear out of a redistributive barter economy. Notice that Clower and Hicks' approaches are not necessarily in conflict.

This essay emphasizes the importance of the geographical spread and contributes to the literature by writing a spatial general equilibrium model to analyze the circumstances under which a monetary economy dominates over a redistributive barter economy in which there is not an absence of double coincidence of wants problem. The environment is a city where specialized commodity producers trade with a centralized merchant to acquire goods for consumption; exchange is costly; individuals do not trust each other and act in their own interest to maximize their utilities.

The model is used to address a number of issues in monetary economics like explaining the historical emergence of a medium of exchange, valued fiat money, the welfare-enhancing role of money, equilibria with several mediums of exchange, and the split between the utility and the medium of exchange value of the good universally accepted as a medium of exchange. The model also provides some interesting links between the monetary and urban economics literatures; for example, it shows how the emergence of a medium of exchange affects the city growth and raises questions about the creation of new cities or marketplaces. 
Section II develops a spatial general equilibrium model to analyze a redistributive barter economy. In this model, goods are sent to a central market and then redistributed among individuals wanting to consume all available goods. To trade successfully, producers must pay transport costs. Exchange is made through barter. Section III shows a spatial monetary general equilibrium model in which some individuals specialize in transport services. The emergence of carriers causes frictions among individuals that are overcome with the appearance of a medium of exchange.

In Section IV, we analyze the conditions under which a monetary economy dominates over a redistributive barter economy. We prove that the emergence of money contributes to economic growth by lowering transport costs and inducing the creation of new goods. In addition, an economy with a more diverse set of goods creates conditions in which money becomes more desirable from a social point of view. This section also uses the model to address a number of issues in monetary and urban economics. Section V concludes.

\section{THE REDISTRIBUTIVE BARTER ECONOMY}

The main features of a redistributive barter economy can be summarized as follows. Consider a city with a central market place in which a number of individuals work; they produce nothing, but devote their whole time availability to facilitating exchanges. Commodity producers operate outside the market center and each of them specializes in producing one different good. To acquire all the goods he needs for consumption, each producer spends a share of his time transporting his output to the market center, where he must barter it with a centralized merchant. As population grows, new industries and varieties appear, and therefore the number of different goods that every individual wants to consume. The transaction cost in this economy is represented by the transport cost and the cost of having centralized merchants. For small 
economies, this system works smoothly. Yet, as population grows, the scope of the economy increases substantially, and the transaction costs may become cumbersome.

In this section, we write a model that attempt to capture the main features of the redistributive barter economy described above. Yet, in order to make the model analytically tractable, some simplifying assumptions are necessary.

\section{Assumptions of the Model}

Consider a narrow city developed on a line along a river that flows from location zero to location $G_{b}$. There is a continuum of $L$ individuals living in that city, and each of them specializes in either production or exchange activities. At location zero, there is a market place where individuals physically meet for barter purposes.

Producers operate outside the market center, and each of them consumes one unit of land. Every producer locates in a different location and specializes in manufacturing only one different good, so producers can be identified by their location in the interval $\left[0, G_{b}\right]$, and also the good that they produce. Assuming that the density land distribution is constant and equal to unity, we have that the number of producers is equal to the city size, $G_{b}$. Producers work in a monopolistic competitive market, so they maximize price and there is free entry.

An often-undesirable feature of spatial monopolistic competitive models is that producers' equilibrium income varies across locations ${ }^{1}$. To avoid the complications of dealing with unequals and keep the model mathematically tractable, we introduce land and a redistributive government. Therefore, there are to be assumed that the government owns the land for the city and leases it to producers at the competitively determined rent $R(i)$ at each location $i$; then, it distributes the revenue from land equally among rent payers, that is, producers. In this way, all producers have the same equilibrium income.

\footnotetext{
${ }^{1}$ See Fujita et. al. (1999, chapter 4) for a discussion.
} 
The Government also possesses and administers a big storehouse in the market center and hires $F_{b}$ individuals to play the role of centralized merchants. The storehouse is organized in such a way that the centralized merchants receive the goods that any individual brings and barter it for a bundle with all the consumption goods that the individual wants ${ }^{2}$. We also assume a full employment condition, so $L=G_{b}+F_{b}$.

There is also a homogeneous good. To avoid modelling a separate industry for homogeneous goods and for the purpose of this model, it is enough to assume that homogeneous goods are not produced; they are some little yellow rocks that are around and individuals like to wear for decoration; thus, they are valuable. Let $M$ be the supply of these yellow rocks, which is exogenously determined. Assume that the yellow rocks do not depreciate and have a zero transport cost. We take them as numeraire. However, they are not used as a medium of exchange, and therefore, cannot be considered as money.

Producers send their output to the market center, and barter with the storehouse the only good they produce for all other goods they need for consumption. Producer $j$ quotes his merchandize at a price $P_{j}$, and the storehouse charges a markup $\xi$ for its intermediation service, so consumers pay a price $\xi P_{j}$ for one unit of good $j$. Notice that the storehouse charges the markup even for homogeneous goods ${ }^{3}$. No one can transport goods upstream and there is free mobility of factors.

\footnotetext{
${ }^{2}$ We can set up a similar model and obtain the same equilibrium if instead, we allow individuals to work as independent centralized merchants in a competitive market. In this case, merchants receive the merchandize unevenly, and to satisfy producers demand they must barter among them. Thus, two markets appear: a market between merchants and producers and a market among merchants. This complicates substantially our story without providing any additional insight for the purpose of this model. After all, as emphasized by Renfrew and Bahn (1996, pp. 351-353), redistributive market economies in primitive and ancient economies worked mainly through a strong central authority that played the role of a centralized merchant.

${ }^{3}$ This leads to the very interesting situation where an individual can exchange $\xi$ units of little rocks with the merchant for only one unit. This resembles the exchange currency market where financial firms buy and sell currencies at different prices, and the difference represents the price that financial firms charge for their intermediation services.
} 
Thus, as suggested by Hicks (1989), there is a city, a government, a market center where individuals go to physically meet other individuals for barter purposes, and a good that people use as a unit of account but not as a medium of exchange. We refer to this economy as the Redistributive Barter Economy (RBE).

\section{Consumers}

An important feature of the economy we want to model is that the number of different goods or varieties that every individual consumes to be an increasing function of the total number of goods available for consumption. Although individuals do not necessarily need to consume every single good that pops up into the market, for the sake of simplicity, we assume that they do it, so suppose that individual $i$ has the following CES utility function

(1) $U^{i}=\left(\int_{0}^{G_{b}}\left(c_{j}^{i}\right)^{\rho} d j\right)^{\alpha / \rho}\left(c_{m}^{i}\right)^{1-\alpha}$,

where $c_{j}^{i}$ and $c_{m}{ }^{i}$ represent individual $i$ 's consumption of good $j$ and little yellow rocks, respectively. The parameter $\rho$ represents the intensity of the preference for variety in manufactured goods, and $\sigma=1 /(1-\rho)$ is the constant elasticity of substitution between any two differentiated products. As $\rho$ decreases toward to zero, $\sigma$ tends to one, and the desire to consume a greater variety of manufactured goods increases.

Suppose that individual $i$ has an income $Y_{i}$, and incurs no cost to transport himself or the consumption goods back home. Let $P_{j}$ be the delivered price of good $j$. Then, individual $i$ 's problem is to maximize the utility function (1) subject to the budget constraint ${ }^{4}$

$$
Y_{i} \geq \xi\left(c_{m}^{i}+\int_{0}^{G_{b}} P_{j} c_{j}^{i} d j\right)
$$


As usual in Dixit-Stiglitz type models, the consumer price index is $\xi H_{b}$, where $H_{b}$ is the manufactured good price index in the RBE,

$$
H_{b}=\left(\int_{0}^{G_{b}} P_{j}^{1-\sigma} d j\right)^{\alpha /(1-\sigma)}
$$

Then, from the first order conditions, we obtain the individual $i$ 's consumption functions for the yellow rocks and for each variety of goods:

$$
c_{m}^{i}=(1-\alpha) Y_{i} / \xi \quad \text { and } \quad c_{j}^{i}=\alpha Y_{i} \frac{P_{j}^{-\sigma}}{\xi H_{b}^{1-\sigma}} .
$$

\section{Producers}

To ship their output to the market center, producers incur in some transport costs that take the Samuelson (1952)'s iceberg form: if one unit of $\operatorname{good} j$ is dispatched from location $j$ to the market center, only a fraction $(1-\tau j)$ arrives, $0<\tau<1$; the rest evaporates in transit.

Suppose also that producers' only input is labor, measured in units of time. The producer located at $j$ produces $x_{j}$ units of good $j$, quotes every unit for a price $P_{j}$ and incurs in the following labor cost: $l_{j}=a+b x_{j}$, where $a, b>0$. Assume that the producer acts as a monopolistic competitive firm. Let $W_{j}$ be the remuneration that he obtains for every unit of labor spent in production and transport. The profit function is

$$
\pi_{j}=(1-\tau j) P_{j} x_{j}-W_{j}\left(a+b x_{j}\right) \text {. }
$$

Since the individual is at the same time the owner and only worker of the firm, the labor remuneration is the break-even wage at $j$, so there is zero profit. In other words, producer $j$ works $l_{j}$ units of time to produce $x_{j}$ units of good $j$; then, he quotes the merchandize for a value equal to $(1-\tau j) P_{j} x_{j}$ at the market center, which at the same time is equal to his labor remuneration.

\footnotetext{
${ }^{4}$ Since the little rocks do not perish and have a fixed supply $M$, individuals do not need to acquire them every period. However, for simplicity, assume that individuals use them every period and after, they throw them away in a place
} 
In equilibrium, the output of every good is consumed by all individuals. Therefore, the following condition must hold

$$
(1-\tau j) x_{j}=\int_{0}^{L} c_{j}^{i} d i, \quad j \in\left[0, G_{b}\right]
$$

If the price of one good has no effect on the demand for other goods, the profit-maximizing price for the producer located at $j$ is

$$
P_{j}=\frac{b W_{j}}{\rho(1-\tau j)}
$$

This means that producer $j$ sets a higher price for good $j$ the farther away the production site is. From the zero profit condition, we find individual's output, $x_{j}=a(\sigma-1) / b$. Since $a, b$ and $\sigma$ are the same for all firms, we can use the shorthand $x$ to refer to producers' output. Thus, every individual's labor is determined as $l=a \sigma$. Yet, we are free to choose units of measurement for labor, so we proceed as in Fujita, Krugman and Venables (1999, Chapter 4) and set the fixed input requirement $a$ to satisfy $a \sigma=1$, that is, every producer spends one unit of labor in production, $l=1$. We regard this amount of labor as producer's labor endowment.

Since the government redistributes the revenue from land among rent payers, each producer $j$ obtains an income $Y_{j}=W_{j}-R(j)+T D R / L$. The free mobility assumption guarantees that this income is constant; otherwise, producers would have an incentive to move and the land rent would increase in the higher income locations. On the other hand, the free entry condition assures that producers and merchants will have the same equilibrium income. This allows dropping the subscript in individuals' income and denoting it simply by $Y$.

\section{The Centralized Merchant}

where merchants can easily pick them up and resell at no cost. 
The Government administers the storehouse that assembles bundles of goods to barter with producers. Each bundle contains producers' consumption demand for every particular good, that is, it contains $c_{m}$ units of little rocks and $c_{j}$ units of $\operatorname{good} j$, for $j \in\left[0, G_{b}\right]$. To provide its service as an intermediary, the storehouse hires $F_{b}$ centralized merchants who obtain the same income as producers, $Y$.

Since the storehouse charges a markup $\xi$ to finance their intermediation activities, it obtains an income $(\xi-1)\left(c_{m}+\int_{0}^{G_{b}} P_{j} c_{j} d j\right) L$. Using individuals' budget constraint, this can be rewritten as $(1-1 / \xi) Y L$. Government budget equilibrium requires that $(1-1 / \xi) Y L=F_{b} Y$. Therefore, $\xi=L /\left(L-F_{b}\right)$. The full employment condition assures that population must distribute between producers and merchants, $L=G_{b}+F_{b}$. Thus, the markup can be written as $\xi=L / G_{b}$, that is, the equilibrium markup is the ratio between population and producers.

Assume that the storehouse owns a constant return to scale technology, that is, each if it hires $F_{b}$ workers, it can barter up to $K F_{b}$ units of manufactured goods, regardless of their variety. Since the storehouse intermediates the whole production between producers and consumers,

$$
F K=x \int_{0}^{G_{b}}(1-\tau j) d j
$$

Considering (4) and the full employment condition, we obtain the equilibrium number of producers and merchants in the $\mathrm{RBE}$

$$
G_{b}(L)=\eta-\sqrt{\eta^{2}-\frac{2}{\tau} k L} \quad \text { and } \quad F_{b}(L)=L-\eta+\sqrt{\eta^{2}-\frac{2}{\tau} k L}
$$

where $k=K / x$ and $\eta=(1+k) / \tau$. Notice that $F$ is positive only if $k>1 / 2$. This represents the minimum level of intermediation technology to guarantee the existence of merchants. Assume that the economy has already reached this minimum of efficiency. Taking derivatives with 
respect to $L$, it can be easily checked that $G_{b}{ }^{\prime}, G_{b}{ }^{\prime}$, and $F_{b}$ ' are positive, and $F_{b}{ }^{\prime \prime}$ is negative. In addition, with a bit of calculus, we can prove that the number of merchants increases and the number of producers decreases as transport cost $(\tau)$ increases or the merchant capacity decreases $(K)$. This reflects the costs of transport and barter activities in the economy.

\section{City Growth and Transport Costs}

Let's analyze how the economy behaves as the city grows. Since all individuals obtain the same equilibrium income, all of them consume the same amount of every single good, that is, every individual consumes $(1-\tau j) x / L$ units of $\operatorname{good} j$, and wear $M / L$ units of little rocks. Thus, we can use (1) and some calculus to write individuals' equilibrium indirect utility as

$$
U_{r b e}=A_{0} \frac{M^{1-\alpha}}{L}\left[1-\left(1-\tau G_{b}(L)\right)^{2-1 / \sigma}\right]^{\alpha \sigma /(\sigma-1)}
$$

where $A_{0}=\left(\frac{\sigma}{\tau(2 \sigma-1)}\right)^{\alpha \sigma /(1-\sigma)} x^{\alpha}$. Notice that the $U_{r b e}$ is not well defined when $G_{b}(L)>1 / \tau$. This occurs because producers cannot bring their output from locations farther than $1 / \tau$, and so the city cannot grow to more than that distance. This also imposes an upper bound to the city population, which can be obtained by substituting $G_{b}$ by $1 / \tau$ in (5). This leads to the following theorem:

Theorem 1: The scope of the economy $\left(G_{b}\right)$ in the RBE is bounded by $1 / \tau$, and population cannot grow to more than $L_{\max }=\frac{1}{\tau}+\frac{1}{2 \tau k}$.

The following theorem gives some additional features of the utility function in the RBE.

Theorem 2: The equilibrium utility function in the RBE has the following features:

i) $U_{r b e}$ tends to zero as $L$ tends to zero;

ii) $U_{r b e}$ tends to $\frac{2 k \tau A_{0}}{2 k+1}$ as $L$ tends to the maximum possible population in the RBE, $L_{\text {max }}$;

iii) $U_{r b e}$ is an increasing function with respect to population. 
Proof: see Appendix A.

It is noteworthy to make several comments about the redistributive barter economy (RBE). First, centralized merchants allow overcoming the absence of a double coincidence of wants problem without the need of a medium of exchange. Second, the individual does not need to spend time searching for other individuals for bartering as in the unstructured barter, so he can devote more time to produce. However, he must gives up a share of his production to a merchant who facilitates the exchange; this reflects the barter cost. Third, the city cannot grow to more than $1 / \tau$. The limitation comes because the transport cost to the market center makes it impossible to produce beyond this radius.

\section{THE MONETARY ECONOMY WITH CARRIERS}

Suppose that there are economies of scale in transportation. An individual, for example, can visit several producers in the same trip and lower the unit transport cost from the producer's place to the market center. This is an incentive for somebody to become a carrier. If producers hire a carrier, they specialize even more, and may increase their consumption and utility level. Yet, if they obtain benefits from lowering transport costs, they may be willing to pay a carrier a fee for transporting their output to the market center.

Suppose, as Gale (1978) emphasizes, that the producer does not trust the carrier; he is afraid that the carrier runs away with his output. Suppose also that carriers do not own all the consumption goods that producers need; however, they want to make a deal. The lack of trust also discards the possibility of credit. Yet, since the merchant accepts to barter any good, there is a possible arrangement: the carrier may give the producer some other good for an equivalent value. Producers will not accept in exchange any other commodity with the same characteristics since they would face the same transport cost, but they will accept valuable little rocks in 
exchange since they will not carry an additional cost for them. They can take the little rocks, go to the market center at no cost, and exchange them at the central market for the consumption goods that they need. The storehouse accepts the little rocks because they store value and can be used to pay carriers; and carriers accept the little rocks because they need them to deal with producers. Therefore, everyone accept little rocks as a medium of exchange because others also do it as well (Menger 1892), and a monetary economy emerges.

Assume that producers accept to deal with carriers and receive the little rocks in exchange; then, the economy behaves in the following way: producers sell their output to carriers at a price $P$. Since little rocks have no transport cost, producers spend their whole time on production activities; the carrier exchanges in the storehouse all the merchandize she brings for consumption goods and some little rocks that he will exchange later with producers. The carrier quotes each unit of merchandize at a delivered price $\gamma P$, where $\gamma$ represents the carrier's markup.

The storehouse sells the consumption goods to all individuals and charges a markup $\xi$. As assumed before, individuals incur no cost of transporting themselves and bringing the consumption goods back home. Since homogeneous goods (little rocks) are used mainly as mediums of exchange, we can refer to them as money. We refer to this economy as the Monetary Economy with Carriers (MEC).

\section{Consumers, Producers and Merchants' Behavior}

Consumers, producers and merchants behave similar in the MEC and in the RBE. However, there are two important differences. First, since producers do not bear the transport cost, all of them behave similar in the MEC; therefore, they quote the same price and obtain the same income. Second, merchants pay now the carrier's markup and consumers pay $\xi \gamma P$ to acquire one unit of any consumption good. The consumer price index is $\xi \gamma H_{m}$, where $H_{m}$, the manufactured 
price index at the producer level in the MEC, is defined as in (2). The individual's consumption functions for the homogeneous and manufactured goods become

$$
c_{m}=(1-\alpha) Y / \xi \gamma, \quad \text { and } \quad c_{j}=\alpha Y \frac{P^{-\sigma}}{\xi \gamma} H_{m}^{\sigma-1}
$$

respectively. Producers' output is the same as in the RBE, but the equilibrium condition of good $j$ changes to $x=\int_{0}^{L} c_{j} d i$, the profit-maximizing price to $P=b Y / \rho$, and individuals' income to $Y=\left(\frac{\alpha L}{\gamma^{\xi}}\right)^{1 /(\sigma-1)} x H_{m}$. Since these variables do not depend on location, producers have no incentive to pay more than the agricultural rent. Therefore, the emergence of a medium of exchange works as a centrifuge force against agglomeration and makes other factors, like those usually studied in urban economics and that we do not considered here, to be the main determinants of the land rent.

Using a similar argument as in the RBE, we can prove that merchants' markup is still $\xi=$ $L /(L-F)$, but condition (4) becomes

$$
F K=G_{m} x .
$$

\section{Carriers' Behavior}

Suppose that each carrier owns a wheelbarrow with a capacity to transport $R$ units of manufactured goods, regardless their variety. To collect the merchandize, each carrier makes only one trip starting at location $G$; he stops at every location on the way until he arrives to the market center. Therefore, they have economies of scale in transportation. It is apparent that each carrier's capacity is at least as large as producers' is, so the city can grow beyond the limitations imposed by the RBE. Assume that carriers' only cost is labor. They buy one unit of merchandize for price a $P$, and sell it to the merchant for $\gamma P$. Let $T$ denote the number of carriers. Since all 
carriers are similar, in equilibrium, each of them trades the same amount of merchandize, $G x / T$. Thus, the carrier's profit is $\pi_{t}=(\gamma-1) P G_{m} x / T$. Assuming that they behave competitively, the free entry condition implies that $\pi_{t}=Y$, so

$$
\gamma=1+\frac{T}{G_{m}}
$$

In equilibrium, all carriers together intermediate total output between producers and merchants, therefore $T R=G_{m} x$. From this identity, (7) and the full employment condition, $L=G_{m}+T_{m}+F_{m}$, we obtain the equilibrium number of producers, carriers and merchants in the MEC,

$$
G_{m}(L)=\frac{k r}{k r+r+k} L, \quad T_{m}(L)=\frac{k}{k r+r+k} L, \text { and } \quad F_{m}(L)=L-\left(\frac{k r+k}{k r+r+k}\right) L,
$$

respectively, where $r=R / x$, is defined similarly as $k$. Therefore, carriers and merchants' markups can be written as $\gamma=1+x / R$ and $\xi=1+r /(k r+k)$ respectively.

\section{Money Demand}

In the MEC, all individuals demand money to facilitate transactions. Each producer demands $x P$ little rocks from the carrier, so all producers together demand $x P G_{m}$ units of money. Carriers demand $\gamma x P G_{m}$ units of money from merchants in exchange for producers' production and, merchants demand $\xi \gamma x P G_{m}$ units of money from consumers. Then, the aggregate money demand is $M^{D}=[1+\gamma(1+\xi)] x P G_{m}$. In addition, individuals demand $(1-\alpha) L Y$ units of homogeneous good due to its non-monetary utility. Thus, in equilibrium, we have

$$
M=(1-\alpha) L Y+\frac{P Q}{v}
$$

where

$$
v=\frac{\xi \gamma}{1+\gamma+\xi \gamma} \text { and } Q=\xi \gamma x G_{m} .
$$


This is a commodity money version of the quantitative equation. The term $P Q / v$ represents the demand of little rocks for transaction purposes, $Q$ the aggregate output of good and services, and $v$ the velocity of money. Notice that, if the utility value of little rocks vanishes, $\alpha$ tends to one, the little rocks become fiat money, and the commodity-money quantitative equation reduces to the well-known quantitative equation for fiat money, $M v=P Q$.

The commodity-money quantitative equation allows finding the manufactured good equilibrium price index in the MEC,

$$
H_{m}=\frac{\alpha^{1 /(1-\sigma)}}{(1-\alpha) L+(b / \rho)(Q / \nu)} G_{m}^{1 /(1-\sigma)} \frac{M}{x} .
$$

An interesting result appears when we compare this expression with the manufactured good equilibrium price index in the RBE, which has the following form (see Appendix A),

$$
H_{b}=\frac{\alpha^{1 /(1-\sigma)}}{(1-\alpha) L}\left[\int_{0}^{G_{b}}(1-\tau j)^{1-1 / \sigma} d j\right]^{\sigma /(1-\sigma)} G_{b} \frac{M}{x}
$$

Two effects are worthy to comment. First, the emergence of carriers allows increasing producers' output, so the homogeneous good supply relative to manufactured goods' decreases, and so it does the price index of manufactured goods. This is reflected in the equation from the fact that $\tau$ becomes zero in the MEC, so the integral term times $G_{m}$ in $H_{b}$ reduces to $G_{m}^{1 /(1-\sigma)}$.

The other effect is that the medium of exchange use of little rocks increases their demand, so $H_{m}$ decreases. This means that the little rocks become more expensive in terms of manufactured goods and therefore, they increase their capacity to store value. This is reflected in the term $(b / \rho)(Q / b)$ that appears in the denominator of the first term in $H_{m}$.

\section{Valued Fiat Money}

The analysis above gives an explanation to the emergence of a commodity money economy. Suppose now that this economy already exists, so $H_{m}$ is the manufactured good equilibrium price 
index, and the little rocks are valued for both its medium of exchange use and its intrinsic utility. Suppose now that, for any reason, the little rocks loose all their utility value, i.e., that they cannot be used for decoration anymore; then, $\alpha$ becomes one and the manufactured good equilibrium price index reduces to

$$
H_{m}=(\rho / b) \frac{v M}{x Q} G_{m}^{1 /(1-\sigma)}
$$

Notice that even though they do not have utility value anymore, the little rocks still keep their value due to their medium of exchange use, that is, they have become valued fiat money.

In practice, individuals had some green papers that could be freely exchanged by gold or silver. Then, an individual could use these green papers as medium of exchange or convert them into gold that provide him some utility; when a government suspended convertibility, these green papers lost their utility value, but still kept their medium of exchange value. Notice, however, that this valued fiat money emerges out of a commodity money system and not directly from a redistributive barter system.

\section{THE MONETARY AND THE BARTER ECONOMIES COMPARED}

In equilibrium, all individuals reach the same income in the MEC, so each of them consumes $x / L$ units of each manufactured good and homogeneous goods. However, since they now use some little rocks as mediums of exchange, they wear a lower amount of little rocks. The reason is that the relative value of the little rocks increases. Making use of (9), we can rewrite the equilibrium indirect utility in the MEC as

$$
U_{m e c}=x^{\alpha}\left(\frac{(1-\alpha) Y}{\xi \gamma}\right)^{1-\alpha}\left(\frac{k r}{k r+r+k}\right)^{\alpha \sigma /(\sigma-1)} \frac{\alpha}{L^{\frac{\sigma-1}{2}}}
$$

This is an expression of individuals' utility as a function of producers, carriers and merchants' technology, and population. $U_{m e c}$ is an increasing function with respect to $L$. Notice that, in the 
MEC, the city growth has now the limitation imposed by the carrier's capacity to transport production to the market center. This capacity is at least as large as in the RBE.

To compare the utility functions in the RBE and in the MEC, consider $\Delta U=U_{\text {mec }}-U_{r b e}$. If this difference is positive, the MEC dominates over the RBE and a monetary economy prevails. Otherwise, the RBE dominates and no money is around. Therefore, from (5), (6) and (10), a monetary economy dominates if

$$
A_{1} L>\left[1-\left(1-\tau G_{b}(L)\right)^{2-1 / \sigma} \mid c_{r m}^{(1-\alpha)(\sigma-1) / \alpha \sigma} .\right.
$$

where $A_{1}=\tau(2-1 / \sigma)\left(\frac{k r}{k r+r+k}\right)$, and $c_{r m}$ is the ratio between the consumption of little rocks in the $\mathrm{RBE}$ with respect to the MEC, and is equal to

$$
c_{r m}=\frac{G_{r}}{G_{m}} \frac{Y_{r b e}}{Y_{\text {mec }}}=\frac{G_{r}}{G_{m}}\left(1+\frac{(b / \rho)(Q / v)}{(1+\alpha) L}\right) .
$$

Notice that this ratio is greater than one. There are two reasons for this. The first is that, for a given population, the existence of a monetary economy requires some individuals stop working as producers to become carriers; and therefore, there is a lower variety $\left(G_{r}>G_{m}\right)$. Second, the higher the portion of little rocks used as mediums of exchange, the lower the portion worn by individuals. Thus, there is an opportunity cost of using the little rocks as mediums of exchange lowering equilibrium utility.

How large could be this effect? Assume an elasticity of substitution equals to 5, as in Fujita et. al. (1999). Suppose now that the share of manufactured goods in individuals' budget is $\alpha=0.95$, and $c_{r m}=10$, that is, consumption of homogeneous goods is 10 times bigger in the RBE than in the MEC; then $c_{r m}^{(1-\alpha)(\sigma-1) / \alpha \sigma}$ is equal to 1.1. If the share is even lower, e.g. $\alpha=0.99$, $c_{r m}^{(1-\alpha)(\sigma-1) / \alpha \sigma}$ becomes 1.018. If $c_{r m}$ strongly increases to $100, c_{r m}^{(1-\alpha)(\sigma-1) / \alpha \sigma}$ only goes up to 1.03 . These quantities are close to one and suggest that this is a small effect that we will ignore in the 
rest of the section. However, what is worthy to stress that the good chosen as a medium of exchange cannot represent an extremely important share of individuals' budget. Otherwise, the opportunity cost of holding commodity money would be higher than the advantage of an increasing volume of trade and diversification. Thus, assume that $c_{r m}^{(1-\alpha)(\sigma-1) / \alpha \sigma} \approx 1$; so a monetary economy dominates if

$$
A_{1} L>1-\left(1-\tau G_{b}(L)\right)^{2-1 / \sigma}
$$

Notice that both terms in (11) become equals to zero as $\tau$ vanishes. Therefore, a necessary condition for a monetary economy to dominate over a redistributive barter economy is that manufactured goods have a positive transport cost. Let's define the following two functions

$$
F_{1}(L)=A_{1} L \quad \text { and } \quad F_{2}(L)=1-\left(1-\tau G_{b}(L)\right)^{2-1 / \sigma}
$$

Based on (11) we obtain the following results.

Theorem 3: The RBE dominates over the MEC for small populations.

Proof: This occurs if $F_{1}(L)<F_{2}(L)$ for a small populations. Since $F_{1}$ and $F_{2}$ are both continuous functions and $F_{1}(0)=F_{2}(0)=0$, to prove this theorem it is enough to show that $F_{1}^{\prime}(0)<F_{2}{ }^{\prime}(0)$.

$F_{1}(L)$ is a straight line that passes through the origin with a positive slope $A_{1}$. Taking derivatives of $F_{2}(L)$ with respect to $L$, we have $F_{2}{ }^{\prime}(L)=\tau(2-1 / \sigma)\left(1-\tau G_{b}(L)\right)^{1-1 / \sigma} G_{b}{ }^{\prime}(L)$; from this and (5) we have $F_{2}{ }^{\prime}(0)=(2-1 / \sigma) \frac{k}{1+k}>\tau(2-1 / \sigma)\left(\frac{k r}{k r+r+k}\right)=A_{1}=F_{1}{ }^{\prime}(0)$.

Q.E.D.

Let's now inquire what happens when population increase. Since $F_{1}$ and $F_{2}$ are continuous, a sufficient condition for a MEC to eventually dominate over a RBE is that $F_{1}\left(L_{\max }\right)>F_{2}\left(L_{\max }\right)$. Suppose that population reaches $L_{\max }$, the maximum possible population for a RBE. For that population level, using (11) we find that a monetary economy dominates if 


$$
r>\frac{\sigma k}{(\sigma-1) k-1 / 2}
$$

Figure 1 illustrates the conditions under which this inequality holds. Three parameters are involved to explain the dominance of a monetary economy: $\sigma, r$ and $k$. Let's inquire more on this.

\section{FIGURE 1 COMES HERE}

Consider first the asymptotic case where the elasticity of substitution $(\sigma)$ tends to one. Then, the right hand size in (12) tends to infinity and the RBE always dominates over the MEC. The reason is the following. Given a population size, the existence of carriers implies lower variety; therefore, there is more variety in the RBE than in the MEC. If the elasticity of substitution is close to one, the intensity of the preference for variety is very strong, individuals prefer to consume more variety than more quantity regardless the cost, and they will be better off in a RBE than in a MEC. This means that for a monetary economy to exist, there must exist some preference for variety, but it cannot be so strong so as to individuals always prefer variety over quantity.

Let's analyze a less extreme case and suppose now that $\rho$ is positive within some reasonable level; then, the existence of a monetary economy requires a minimum level of the intermediation technology parameters, $r$ and $k$. This is reflected in Figure 1 by the fact that $k$ must be greater than $1 / 2(\sigma-1)$, and $r$ greater than $1 / \rho$. Observe that the higher the merchants' technology, the lower the necessary transport technology for a monetary exchange to emerge. Why? Because the higher the storehouse's intermediation technology, the fewer the number of centralized merchants, and the higher the number of commodity producers and carriers; therefore, the lower the necessary technology the carriers need to transport all the output to the market center. 
Suppose that there exist the technological conditions for a monetary economy to dominate over a barter economy, so inequality (12) holds; then, there exists $L^{*}$ such that $0<L^{*}<$ $L_{\max }$ and $F_{1}\left(L^{*}\right)>F_{2}\left(L^{*}\right)$, and functions $F_{1}$ and $F_{2}$ can be drawn as shown in Figure 2. If population is less than $L^{*}$, nobody has the incentive to become a carrier, individuals are better off if they choose some other occupation, and a barter economy prevails.

\section{FIGURE 2 COMES HERE}

Suppose now that population is greater than $L^{*}$; then, if a barter economy existed, some individuals will soon realize that they can be better off were they became carriers; producers also will realize that they would be better off if they dealt with carriers, and the economy move to an equilibrium in which a monetary economy prevails.

\section{The Historical Emergence of a Medium of Exchange}

Since most anthropologists agree that in all likelihood money emerged out of a redistributive barter economy, as stated in the introduction, this model can be used to provide an explanation to the historical emergence of a medium of exchange.

Although the most standard approach to this problem in modern monetary economics would be to include time explicitly and use a dynamic structure where individuals make rational inter-temporal decisions to determine the exact period when a medium of exchange emerges, this would greatly complicate an already difficult problem, and divert the attention from the central problem we want to consider. After all, as emphasized by Menger (1892), the emergence of a medium of exchange was a process that took several generations. Instead, we take the shortcut of using ad hoc dynamics to deal with population growth effects ${ }^{5}$. Think of an economy evolving by a two-step process. At the beginning, individuals are in equilibrium and use a particular exchange

\footnotetext{
${ }^{5}$ Fujita, Krugman and Venables (1999, chapter 1) suggest this procedure to analyze the effects of population growth. They provide an extensive discussion about the use of ad hoc dynamics in the new economic geography and the
} 
system, then increase the population a bit and hold it there; individuals choose their most convenient occupation (producer, merchant or carrier), and therefore the most convenient exchange system; let the economy settle into a new equilibrium; then repeat.

Suppose that the economies of scale in intermediation allow setting equilibrium in a redistributive barter economy (RBE). Let population $(L)$ increase a bit. If $L$ is less than $L^{*}$, individuals reach a higher utility working as manufactured good producers than as carriers, so nobody has the incentive to become a transport service specialist and the economy settles a new RBE equilibrium. Since $U_{\text {mec }}$ increases faster than $U_{r b e}$ after population has achieved a certain size, this process keeps this way until population size surpasses $L^{*}$. After that point, $U_{\text {mec }}$ reaches $U_{r b e}$ and some individuals realize that they can increase their real income if they become carriers; producers also realize that they are better off if they deal with carriers; the economy settles a MEC equilibrium and a monetary economy emerges. Notice that if the RBE still dominates over the MEC at $L_{\max }$, nobody ever becomes a carrier and no money will be ever around.

\section{CONCLUSION}

The model presented above captures the essential role of a medium of exchange. It also shows how a commodity-money emerges endogenously out of a barter economy, and valued fiat money out of a commodity-money economy in a general equilibrium framework. In the model, already specialized individuals interact in a barter economy in such a way that there is no absence of double coincidence of wants, so the economy works smoothly and nobody starves because of the inconvenience of barter. It is shown that even in this economy, there is room for the existence of a medium of exchange. Once the transport technology has reached a certain level and population a certain size, the economies of scale in transport allow some individuals to specialize as carriers

modern evolutionary game theory. Anas and Xu (1999) and Fujita (1988) also use similar ad hoc dynamics to analyze land use patterns; and Anas (1992) and Fujita et. al. (1999, chapter 10) to study the emergence of new cities. 
increasing advantages from trade. Consequently, commodity producers increase the output to be distributed among the whole population, and individuals obtain a higher level of consumption and utility. Without trust, this process causes frictions among individuals that are overcome with the appearance of a medium of exchange with have an intrinsic utility. This result contrasts with the search theoretical models of money where "by becoming more specialized, a producer can increase output per unit of time, but only at the cost of reducing the fraction of consumers who will accept his output in exchange (Kiyotaki and Wright (1993, pg 71)."

The model evidences the welfare-enhancing role of money and provides an explanation to the historical emergence of a medium of exchange. Notice also that for a certain population size and technology, the barter economy dominates over the monetary economy. This may explain why some societies, such as Ancient Egypt or the Incas in Peru kept barter as exchange system. Einzig (1966, pp. 194 and 338) provides a comprehensive analysis of the exchange system in these two great societies.

The model also determines endogenously the good that serves as a medium of exchange. This is a consequence of the relationship between its physical properties and individuals' optimization behavior.

Notice also that the existence of several low transport cost goods can give rise to equilibria with several mediums of exchange. Suppose that there exist, for example, two different homogeneous goods with the same physical properties, in particular, zero transport cost and perishability rate, and both enter identically in the utility function. Then, individuals would be indifferent between choosing one or both goods as mediums of exchange. This is the case of gold and silver that were widely used as mediums of exchange as soon as technical progress allowed them to give utility to individuals, and acquire some other physical properties like measurability and divisibility. This conclusion is supported by anthropological findings of primitive economies 
in which several goods simultaneously served as mediums of exchange. Some examples of these are the use of shells and teeth as money in the Solomon Islands, barley and silver in Babylon and Assyria, shells and silk in China, and several metals in many ancient societies. Einzig (1966) provides an extensive list of examples.

Commodity money is valued for its intrinsic utility and its medium of exchange property; but once this money loses its utility value, its medium of exchange value remains and therefore it becomes fiat money. Notice also that the emergence of carriers and a medium of exchange come together, so the frictions among individuals that this process may cause never becomes a real problem.

It is worthwhile that producers' price is not proportional to the supply of the medium of exchange in case of a commodity money economy, but it does it in case of fiat money. On the other hand, the relative number of carriers and merchants with respect to population determine markups, and carrier and merchant's technology determine these ratios.

Another interesting feature of this model is that it provides a natural link between the monetary and urban economics literatures. In fact, the emergence of a medium of exchange allows population to increase beyond the limitation imposed by the barter technology, and the limit to the city growth is imposed for the carrier's capacity to transport production to the market center. This allows the creation of more goods than the maximum possible for a barter economy with merchants. In other words, the emergence of a medium of exchange may cause an increase not only in production and individuals' utility, but also in the city size and the scope of the economy. Notice that once the economy adopts a medium of exchange, an increase in the amount of little rocks does not affect the aggregate production. However, it increases individuals' utility since it cheapens homogeneous goods; but once the economy adopts fiat money, this real effect also vanishes. 
Finally, an interesting inquiry is to relate population growth and migrations in this context. From Anas (1992)' analysis on the birth and growth of cities, it follows that individuals have no incentive to create a new city since equilibrium utility never falls to zero again, but they may want to migrate to other emerging cities, delaying the emergence of a medium of exchange. They also might also want to create new marketplaces, as Berliant and Konishi (2000) endogenously determine, and start trading among different marketplaces. In this case, a medium of exchange could emerge through the trade among different market places. Although this could be the case of a number of economies that adopted some kind of money in an early stage of development, the historical evidence shows that definitely it was not what occurred in the Ancient Egypt and the Inca societies. These cases are not considered in this model since the number of market places and cities are exogenously determined, so we leave the problem for future research.

\section{REFERENCES}

Anas, A. (1992). "On the Birth and Growth of Cities: Laissez-faire and Planning Compared." Regional Science and Urban Economics. 22, pg. 243-258. North Holland.

Anas, A. and R. Xu (1999) "Congestion, Land Use and Job Dispersion: A General Equilibrium Model", Journal of Urban Economics.

Berliant, M. and H. Konishi (2000). "The Endogenous Formation of a City: Population Agglomeration and Marketplaces in a Location-Specific Production Economy," Regional Science and Urban Economics, 30, 3, pg. 289-324. North Holland.

Clower, R. W. (1995). “On the Origins of Monetary Exchange.” Economic Inquiry, Vol. 33 October, 525-36.

Duffy J. and Ochs J. (1999). "Emergence of money as a medium of exchange: An experimental study." American Economic Review, 89 (4) September, 847-877. 
Ederer, R. J. (1964). “The Evolution of Money.” Public Affairs Press. (1964).

Einzig, P. (1966). "Primitive Money. In its Ethnological, Historical and Economic Aspects." Pergamon Press. Second Edition.

Fujita, M. (1988). “A Monopolistic Competition Model of Spatial Agglomeration: Differentiated Products Approach”, Regional Science and Urban Economics, 18, 87-124.

Fujita, M., P. Krugman and A. J. Venables (1999). “The Spatial Economy. Cities, Regions and International Trade." The MIT Press, Cambridge, Massachusetts.

Gale, D. (1978). “The Core of a Monetary Economy without Trust." Journal of Economic Theory, 19, 456-491.

Hicks, J. E. (1969). “A Theory of Economic History.” Clarendon Press. Oxford.

Hicks, J. E. (1989). “A Market Theory of Money.” Clarendon Press, Oxford.

Howitt, P. and R. Clower (2000). "The Emergence of Economic Organization," Journal of Economic Behavior and Organization, 41 (1), January, pp. 55-84.

Jevons, W. S. (1875). "Money and the Mechanism of Exchange.” Appleton. London.

Jones, R. A. (1976). “The Origin and Development of Media of Exchange.” Journal of Political Economy, vol. 84, August, pp. 757-75.

Kiyotaki, N. and R. Wright (1989). “On Money as a Medium of Exchange. "Journal of Political Economy, vol. 9, no. 41.

Kiyotaki, N. and R. Wright (1993). "A Search-Theoretical Approach to Monetary Economics," American Economic Review, 83, no. 1, (March): 63-77.

Laidler, D. (1997). "Notes on the Microfoundations of Monetary Economics" The Economic Journal, 107, July, 1213-1223.

Menger, K. (1892). “On the Origins of Money.” Economic Journal, 2, pp. 239-255. 
Polanyi, K. (1957). "The Economy as Instituted Process." in Trade and Market in the Early Empires Economies in History and Theory, Chapter XIII, edited by Karl Polanyi, Conrad M. Arensberg and Harry W. Pearson. The Free Press, New York. Collier-Macmillan Limited, London.

Renfrew, C. and P. Bahn (1996). “Archeology. Theories Methods and Practice.” Thames and Hudson Ltd. Second Edition, London.

Samuelson, P. A. (1952). "The Transfer Problem and the transport Cost: The Terms of Trade when Impediments are Absent," Economic Journal 62: 278-304.

Smith, A. (1776). "An Inquiry into the Nature and Causes of the Wealth of Nations." 2 vols. New York: Kelley. Reprinted 1966.

\section{$\underline{\text { APPENDIX A }}$}

Using the consumption functions (3) and prices $P_{j}=\frac{b W_{j}}{\rho(1-\tau j)}$ into equilibrium condition $(1-\tau j) x_{j}=\int_{0}^{L} c_{j}^{i} d i$, we find producer $j$ 's labor remuneration

$$
W_{j}=\frac{(\sigma-1)(1-\tau j)^{1-1 / \sigma}}{b \sigma \xi^{1 / \sigma}}\left(\frac{\alpha H_{b}^{\sigma-1}}{x} \int_{0}^{L} Y_{i} d i\right)^{1 / \sigma}
$$

This is the break-even labor remuneration at location $j$. On the other hand, every producer's income is equal to the average labor remuneration, $G_{b} Y=\int_{0}^{G_{b}} W_{j} d j$. From this two equations we obtain

$$
Y=\left(\frac{\sigma}{\tau(2 \sigma-1)}\right)^{\sigma /(1-\sigma)}\left(\frac{\alpha L}{\xi G_{b}^{\sigma}}\right)^{1 /(\sigma-1)}\left[1-\left(1-\tau G_{b}\right)^{2-1 / \sigma}\right]^{\sigma /(\sigma-1)} x H_{b} .
$$


Assuming an agricultural rent equal to zero, the market rent functions is

$$
R(j)=\frac{(\sigma-1)}{b \sigma} \xi^{-1 /(\sigma-1)}\left(\frac{\alpha H_{b}^{\sigma-1}}{x} L Y\right)^{1 / \sigma}\left[(1-\tau j)^{1-1 / \sigma}-(1-\tau G)^{1-1 / \sigma}\right], \quad j \in\left[0, G_{b}\right]
$$

In addition, taking derivatives in (5) with respect to population, we have

$$
\begin{aligned}
& G_{b}{ }^{\prime}(L)=\frac{k}{\tau}\left(\eta^{2}-\frac{2}{\tau} k L\right)^{-1 / 2} \quad \text { and } \quad G_{b}{ }^{\prime \prime}(L)=\left(\frac{k}{\tau}\right)^{2}\left(\eta^{2}-\frac{2}{\tau} k L\right)^{-3 / 2} \text {; } \\
& F_{b}{ }^{\prime}(L)=1-\frac{k}{\tau}\left(\eta^{2}-\frac{2}{\tau} k L\right)^{-1 / 2} \quad \text { and } \quad F_{b}{ }^{\prime \prime}(L)=-\left(\frac{k}{\tau}\right)^{2}\left(\eta^{2}-\frac{2}{\tau} k L\right)^{-3 / 2} \text {. }
\end{aligned}
$$

From these expressions, it is apparent that both $G_{b}{ }^{\prime}, G_{b}{ }^{\prime \prime}$ and $F_{b}$ ' are positive, and $F_{b}{ }^{\prime \prime}$ is negative; then, we can use a bit of algebra to prove that the number of merchants increases and the number of producers decreases as transport cost $(\tau)$ increases or the merchant capacity decreases $(K)$, reflecting the cost of transport and barter activities in the economy.

Now, substituting equilibrium markup in $P_{j}$ and $Y$ respectively, we obtain equilibrium prices and individuals' income

$$
P_{j}=\frac{H_{b}}{(1-\tau j)^{1 / \sigma}}\left[\int_{0}^{G_{b}}(1-\tau j)^{1-1 / \sigma} d j\right]^{1 /(\sigma-1)}
$$

$$
Y=\alpha^{1 /(\sigma-1)} \frac{x H_{b}}{G_{b}}\left[\int_{0}^{G_{b}}(1-\tau j)^{1-1 / \sigma} d j\right]^{\sigma /(\sigma-1)}
$$

On the other hand, from the homogeneous good equilibrium condition, $M=(1-\alpha) L Y$. Using this, (A1) and (A2), we obtain the equilibrium manufactured good price index is

$$
H_{b}=\frac{\alpha^{1 /(1-\sigma)}}{(1-\alpha)} \frac{G_{b}}{L}\left[\int_{0}^{G_{b}}(1-\tau j)^{1-1 / \sigma} d j\right]^{\sigma /(1-\sigma)} \frac{M}{x}
$$

Now, we can prove Theorem 2. First, let's define

$$
Z_{2}=1-\left(1-\tau G_{b}(L)\right)^{2-1 / \sigma}
$$


Taking derivatives respect to $L$, we have

$$
\begin{aligned}
& \frac{d Z_{2}}{d L}=\frac{\tau(2 \sigma-1)}{\sigma}\left(1-\tau G_{b}(L)\right)^{1-1 / \sigma} G_{b}{ }^{\prime}(L), \quad \text { and } \\
& \frac{d^{2} Z_{2}}{d L^{2}}=\frac{\tau(2 \sigma-1)}{\sigma}\left(\left(1-\tau G_{b}(L)\right)^{1-1 / \sigma} G_{b}{ }^{\prime \prime}(L)-\frac{\tau(\sigma-1)}{\sigma}\left(1-\tau G_{b}(L)\right)^{-1 / \sigma} G_{b}{ }^{\prime}(L)^{2}\right) .
\end{aligned}
$$

Notice that, as $L$ tends to zero, $d Z_{2} / d L$ tends to $(2 \sigma-1) K / x \sigma \eta$. Since $G_{b}(L)$ is always increasing, $d Z_{2} / d L$ is always positive, so $Z_{2}$ is always an increasing function with respect to $L$.

Now, we can proceed to prove the theorem. Notice that $U_{b e m}(L)=\frac{A_{0} M^{1-\alpha}}{L} Z_{2}^{\alpha \sigma /(\sigma-1)}$, applying the L'Hopital rule, we can check that $U_{r b e}$ tends to zero, as $L$ tends to zero. This proves (i). In addition, by substitution, it can be easily verified that (ii) holds.

Taking the first derivative with respect to $L$, we find that $d U_{r b e} / d L$ is positive if

$$
\frac{\alpha \tau(2 \sigma-1)}{\sigma-1} G_{b}{ }^{\prime}(L) L>0>\left(1-\tau G_{b}(L)\right)^{1 / \sigma-1}-\left(1-\tau G_{b}(L)\right)
$$

since $\sigma>1$ and $\tau G_{b}(L)<1$. Thus, $U_{r b e}$ is always increasing. This proves the theorem.

Q.E.D. 


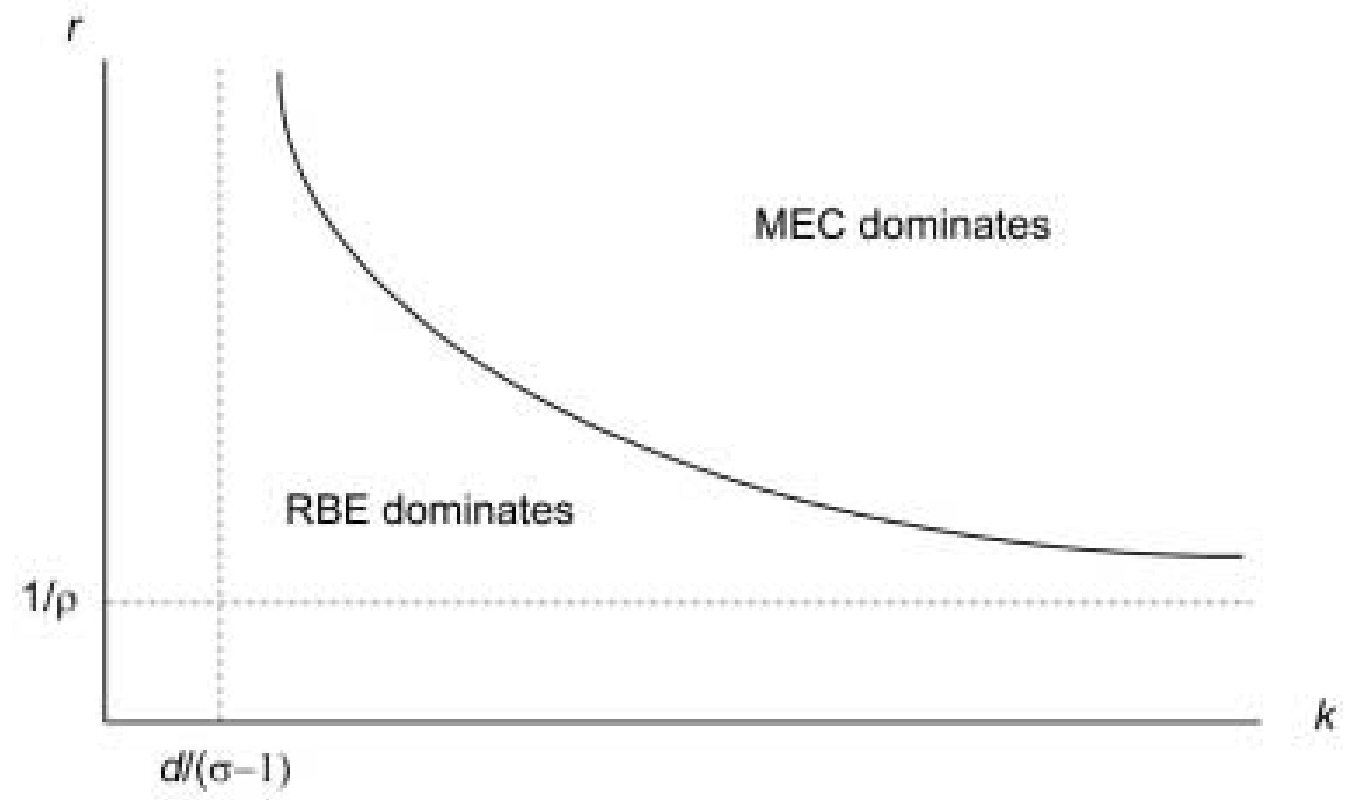

FIGURE 1

CONDITIONS UNDER WHICH THE MEC DOMINATES OVER THE RBE 


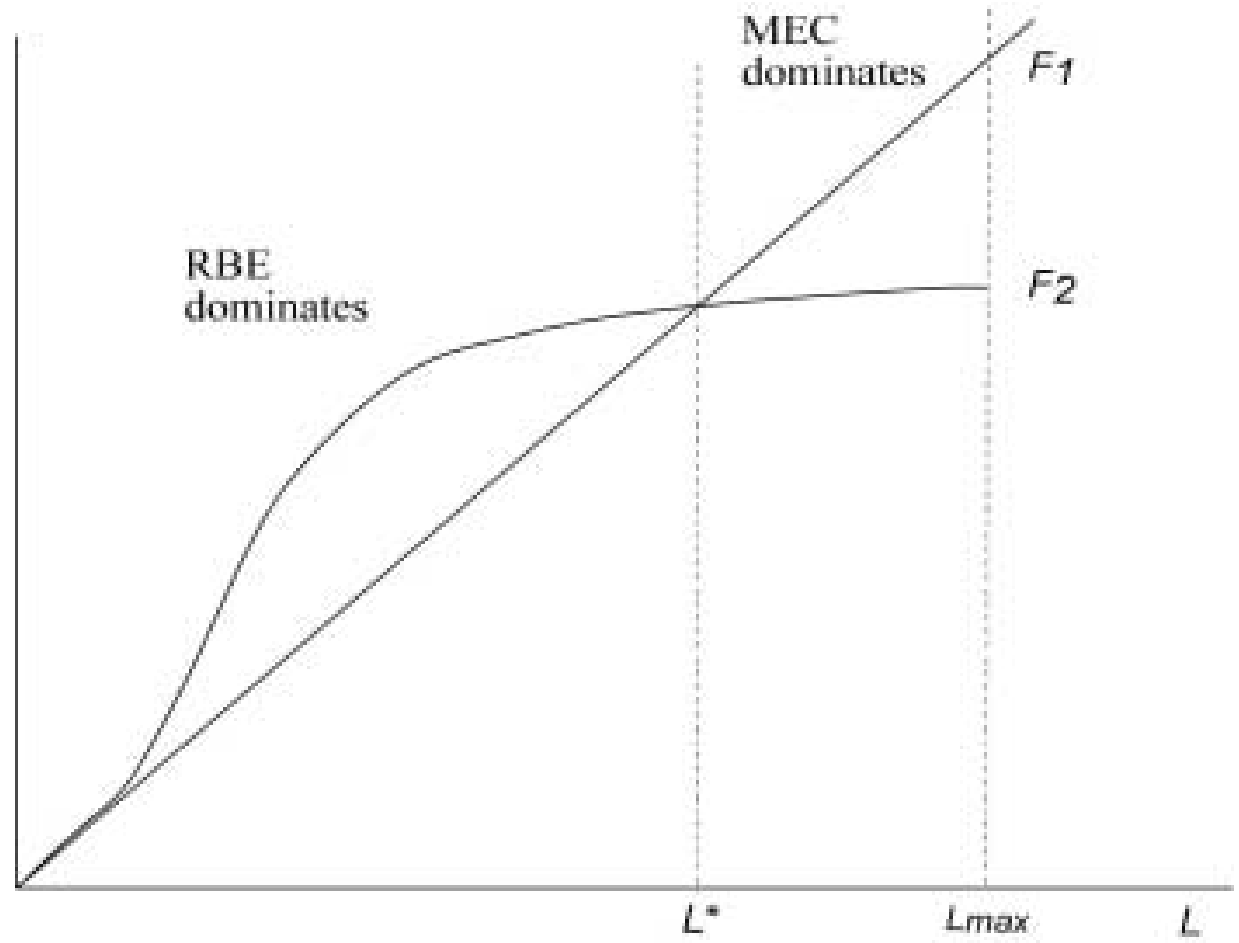

FIGURE 2

THE RBE AND THE MEC COMPARED 